\title{
Increasing of the Accuracy of Signals' Time Parameters Measuring Using Double Pulse Trains
}

\author{
A.V. Isaev ${ }^{1}$, U.V. Suchodolov ${ }^{1}$, A.S. Sushko ${ }^{1}$, A.A. Sheinikau ${ }^{2}$ \\ ${ }^{1}$ Belarusian National Technical University, \\ Nezavisimosti Ave., 65, Minsk 220013, Belarus \\ ${ }^{2}$ Military Academy of the Republic Belarus, \\ Nezavisimosti Ave., 220, Minsk 220057, Belarus
}

Received 06.10.2021

Accepted for publication 01.12.2021

\begin{abstract}
In modern diagnostics, much attention is paid to measuring of time parameters, as well as their change over time. The purpose of this work is to develop a method for measuring of time intervals which made it possible to increase the measurement accuracy by reducing errors associated with the instability of main parameters of the pulse signal.

In the most of approaches used, the error associated with the instability of main parameters of signals under study is not enough taken into account. As an alternative, a spectral method is proposed in which the measurement of time intervals, as well as their changes, is performed based on the analysis of pulse sequences formed on the basis of characteristic points of the measured signal. For this a double pulse sequence was considered, an equation for the amplitudes of its spectral components was obtained, and in accordance with this it was determined that the delay time between double pulses is the most informative parameter.

Using the Mathcad software, an analysis of the sensitivity regions was carried out for the change in the main parameters of the pulse sequence, namely the repetition rate, as the main destabilizing factor.

As a result of the implementation of the developed technique, a structural diagram of the measuring system is proposed and an analysis of the measurement error associated with the instability of the main parameters of the pulse sequence is carried out. This error is estimated to be less than $0.01 \%$.

The considered method makes it possible to increase the accuracy of measuring time intervals due to the almost complete elimination of the influence of the instability of the reference frequency and the amplitude of the generated pulses which is unattainable with modern hardware, including digital signal processing.
\end{abstract}

Keywords: amplitude-frequency spectrum of a pulse sequence, discontinuous pulse sequence, error from parameter instability, delay time in a pulse sequence.

DOI: $10.21122 / 2220-9506-2021-12-4-323-331$

\begin{tabular}{ll}
\hline Адрес для переписки: & Address for correspondence: \\
Исаев А.В. & Isaev A.V. \\
Белорусский национальный технический университет, & Belarusian National Technical University, \\
пр-т Независимости, 65, г. Минск 220013, Беларусь & Nezavisimosti Ave., 65, Minsk 220013, Belarus \\
e-таil: isaеv0302@gmail.com & e-mail: isaev0302@gmail.com \\
\hline Для цитирования: & For citation: \\
A.V. Isaev, U.V. Suchodolov, A.S. Sushko, A.A. Sheinikau. & A.V. Isaev, U.V. Suchodolov, A.S. Sushko, A.A. Sheinikau. \\
Increasing of the Accuracy of Signals’ Time Parameters Measuring & Increasing of the Accuracy of Signals’ Time Parameters Measuring \\
Using Double Pulse Trains. & Using Double Pulse Trains. \\
Приборы и методы измерений. & Devices and Methods of Measurements. \\
2021. - Т. 12, № 4.- С. 323-331. & 2021, vol. 12, no. 4, pp. 323-331. \\
DОI: $10.21122 / 2220-9506-2021-12-4-323-331$ & DOI: 10.21122/2220-9506-2021-12-4-323-331 \\
\hline
\end{tabular}




\title{
Увеличение точности измерения временных параметров сигналов с использованием двойных импульсных последовательностей
}

\author{
А.В. Исаев ${ }^{1}$, Ю.В. Суходолов ${ }^{1}$, А.С. Сушко ${ }^{1}$, А.А. Шейников ${ }^{2}$ \\ ${ }^{1}$ Белорусский национальный технический университет, \\ nр-m Независимости, 65, г. Минск 220013, Беларусь \\ ${ }^{2}$ Военная академия Республики Беларусь, \\ nр-m Независимости, 220, г. Минск 220057, Беларусь
}

Поступила 06.10.2021

Принята к печати 01.12.2021

Измерению временных параметров, в том числе и их изменению, уделяется большое внимание в современной диагностике. Целью данной работы являлась разработка метода измерения временных интервалов, позволившего увеличить точность измерения за счёт уменьшения погрешностей, связанных с нестабильностью основных параметров импульсного сигнала.

В большинстве используемых подходов, мало учитывается погрешность, связанная с нестабильностью основных параметров исследуемых сигналов. В качестве альтернативы предложен спектральный метод, при котором измерение временных интервалов, а также их изменения производится на основе анализа импульсных последовательностей, сформированных на основе характерных точек измеряемого сигнала. Для этого рассмотрена двойная импульсная последовательность, получено уравнение для амплитуд её спектральных составляющих и, в соответствии с этим, установлено, что время задержки между двойными импульсами является наиболее информативным параметром.

Далее с помощью ПО Mathcad проведён анализ областей чувствительности на изменение основных параметров импульсной последовательности, а именно частоты следования, как основного дестабилизирующего фактора.

Как результат реализации разработанной методики, предложена структурная схема измерительной системы и проанализирована погрешность измерения, связанная с нестабильностью основных параметров импульсной последовательности. Данная погрешность составляет менее 0,01 \%.

Таким образом, рассмотренный метод позволяет повысить точность измерения временных интервалов за счёт практически полного исключения влияния нестабильности опорной частоты и амплитуды формируемых импульсов, что недостижимо современными аппаратными средствами в том числе и при цифровой обработке сигналов.

Ключевые слова: амплитудно-частотный спектр импульсной последовательности, прерывистая импульсная последовательность, погрешность от нестабильности параметров, время задержки в импульсной последовательности.

DOI: $10.21122 / 2220-9506-2021-12-4-323-331$

\begin{tabular}{ll}
\hline Адрес для переписки: & Address for correspondence: \\
Исаев А.В. & Isaev A.V. \\
Белорусский национальный технический университет, & Belarusian National Technical University, \\
пр-т Независимости, 65, г. Минск 220013, Беларусь & Nezavisimosti Ave., 65, Minsk 220013, Belarus \\
e-таil: isaеv0302@gmail.com & e-mail: isaev0302@gmail.com \\
\hline Для цитирования: & For citation: \\
A.V. Isaev, U.V. Suchodolov, A.S. Sushko, A.A. Sheinikau. & A.V. Isaev, U.V. Suchodolov, A.S. Sushko, A.A. Sheinikau. \\
Increasing of the Accuracy of Signals'Time Parameters Measuring & Increasing of the Accuracy of Signals' Time Parameters Measuring \\
Using Double Pulse Trains. & Using Double Pulse Trains. \\
Приборы и методы измерений. & Devices and Methods of Measurements. \\
2021. - Т. 12, № 4. - С. 323-331. & 2021, vol. 12, no. 4, pp. 323-331. \\
DОI: $10.21122 / 2220-9506-2021-12-4-323-331$ & DOI: 10.21122/2220-9506-2021-12-4-323-331 \\
\hline
\end{tabular}




\section{Introduction}

One of the most important problems of modern instrumentation is the most reliable measurement of the parameters of the processes under study, i. e. obtaining data with minimal error. And taking into account the possibilities of the modern world, when the parameters and characteristics under study are minimized, this problem becomes more and more urgent. This problem was not spared by the measurement of various time parameters. So the measurement of small time intervals requires not only a high sensitivity of the measured parameters, but also a minimum error from the instability of the generated signals themselves. Measurement of changes in time intervals is widely used for diagnostics of electrical machines, measurement of phase shifts [1-3], determining the distance to objects using radar [4, 5], etc. Currently, there are a large number of methods and techniques for measuring both the time intervals themselves and their changes. Among them, there are both classical approaches to measuring the duration of a time interval by the method of discrete counting, which consists of comparing the measured time interval with a discrete interval that reproduces a unit of time [6], and more modern ones. So, for example, a method for digital measurement of the duration of time intervals, which consists of counting the number of quantizing pulses with a repetition period for specified measurement intervals, when odd and even separate measurement intervals are formed alternating with each other with durations correlated with respect to the period and duration of pulses of the input signal that accumulate the results of filling individual measurement intervals with quantizing pulses [7]. Or a method for measuring time intervals between the moment of triggering the probing signal and the center of the reflected signal, which consists of receiving the reflected signal with subsequent analog-to-digital conversion of this signal from the moment of starting the probing signal, determining the number of the element of the numerical array corresponding to the center of the reflected signal, and creation in its surroundings of the reference signals, which correspond in shape to the reflected one, the center of each of which is shifted relative to the center [8]. A method for measuring time intervals by counting the number of periods of the reference generator within the measured interval is also presented, in which, to increase the measurement resolution, along with the signal of the reference high-sta- bility generator, the signal of an additional auxiliary high-stability generator is used, which is converted into a sawtooth voltage. Further, when processing the signal, the voltage level corresponding to the moment of intersection of the front of the measured event and the front slope of the sawtooth voltage is stored, and generate a sawtooth voltage signal corresponding to this level. Next, the number of pulses is counted until the moment of coincidence of the pulse front in the packet with the pulse front of the reference generator, and the interval between the two events is determined by the corresponding expression [9]. However, the presented methods have the main drawback - this is a significant dependence of the accuracy of measuring the time interval on the technical parameters of the reference oscillators and counters used in the hardware implementation.

When forming and converting pulse signals, it is possible to achieve rather small values of errors. For example, when shaping pulses using existing software-controlled digital means, it is possible to achieve amplitude instability of the order of $0.01 \%$, and the instability of temporal parameters, such as pulse duration, pulse repetition period, and others, can reach $0.0001 \%$. All these parameters, as a rule, are significantly lower than the instability of the master frequency. So, if the measurement is organized in modern equipment based on an industrial or any other network, the instability of which can reach $1 \%$ or more ${ }^{1}$, then all efforts should be directed primarily at reducing the errors from this instability. In this case, it is additionally desirable to reduce the error from the instability of the generated pulses. The commonly accepted practice of measuring time intervals involves the formation of pulse trains and measuring the delay time between them [10]. However, all of the above existing methods for measuring changes in time parameters do not provide for taking into account the instability of the repetition rate of pulse sequences comparable to unstable network parameters.

The purpose of this work was to develop a method for measuring the time intervals of the studied pulse sequences, which significantly reduces the

\footnotetext{
${ }^{1}$ GOST 32144-2013 Elektricheskaya energiya. Sovmestimost' tekhnicheskikh sredstv elektromagnitnaya. Normy kachestva elektricheskoy energii v sistemakh elektrosnabzheniya obshchego naznacheniya. Vveden $\mathrm{v}$ deystviye postanovleniyem Gosudarstvennogo komiteta po standartizatsii Respubliki Belarus' ot 12 marta 2015. № 13 neposredstvenno $\mathrm{v}$ kachestve gosudarstvennogo standarta Respubliki Belarus's 1 fevralya 2016.
} 
error associated with the instability of the driving frequencies, including the study and diagnostics of the state of the windings of electrical machines.

\section{Основная часть}

After analyzing various sequences of pulses with different time parameters, it was found that the most optimal for achieving the goal is a complex discontinuous sequence consisting of two double rectangular pulse sequences. The information parameter for such a sequence will be the delay time between two double sequences. In this case, it is necessary to exclude or minimize the effect on the measurement result of the instability of the repetition rate of these sequences (for example, formed from the current curve of the supply network), from the components of which a pulse sequence is formed. Let us analyze the composition of such a sequence, taking into account the amplitude $E$, the duration of the pulses in the bursts $t_{i 11}, t_{i 12}, t_{i 21}$ and $t_{i 22}$, the repetition period of the double sequences $T$ and the delay time from the beginning of the period: for the first pulse $t=0$, for the second pulse $t=T_{01}$, for the third pulse $t=t_{w}$ and for the fourth pulse $t=t_{w}+T_{02}$ (Figure 1a). Consider our discontinuous pulse sequence as two independent sequences (Figure $1 b$ and $1 c$ ) and set the following conditions:

$t_{i 11}=t_{i 12}=t_{i 21}=t_{i 22}=t_{i}$;

$T_{01}=T_{02}=T_{0}$.

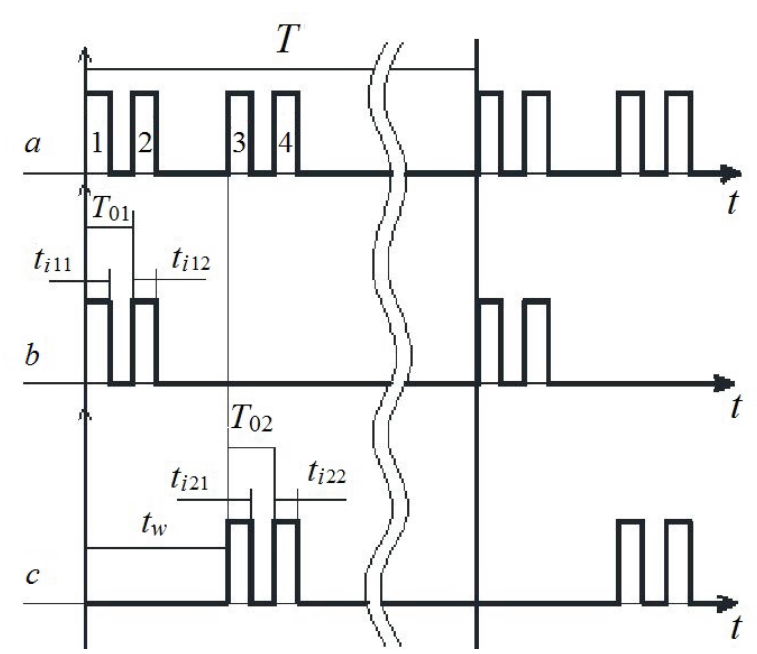

Figure 1 - Double pulse sequence: $a$ - the discontinuous pulse sequence under consideration; $b$-double pulse sequence no. $1 ; c$-double pulse sequence no. 2

Then, according to [11], the complex amplitude of the $n$-th harmonic of each pulse sequence is defined as:
For the first discontinuous sequence with pulses 1 and 2.

The equation for the first pulse has the form:

$U_{1}=\frac{E}{\pi n j}\left(1-e^{-j n \omega t_{i}}\right)$

for the second pulse:

$U_{1}=\frac{E}{\pi n j}\left(1-e^{-j n \omega t_{i}}\right) e^{-j n \omega T_{0}}$.

Considering that:

$U_{p 1}=U_{1}+U_{2}$;

so:

$U_{p 1}=\frac{E}{\pi n j}\left(1-e^{-j n \omega t_{i}}\right)+\frac{E}{\pi n j}\left(1-e^{-j n \omega t_{i}}\right) e^{-j n \omega T_{0}}=$

$=\frac{E}{\pi n j}\left(1-e^{-j n \omega t_{i}}\right)\left(1+e^{-j n \omega T_{0}}\right)$,

where $E$ is the amplitude of the pulses; $T_{0}$ is the period of pulses in the sequence; $t_{i}$ is the duration of pulses; $n$ is the number of the harmonic; $\omega$ is cyclic frequency, determined by the formula:

$\oplus=2 \pi / T$,

where $T$ is the period of the pulse sequence.

If we take into account the displacement theorem [11], then the equation for the second sequence with pulses 3 and 4, equation (3) will have the form:

$$
\begin{aligned}
& U_{p 2}=\frac{E}{\pi n j}\left(1-e^{-j n \omega t_{i}}\right) e^{-j n \omega t_{w}}+ \\
& +\frac{E}{\pi n j}\left(1-e^{-j n \omega t_{i}}\right) e^{-j n \omega T_{0}} e^{-j n \omega t_{w}}= \\
& =\frac{E}{\pi n j}\left(1-e^{-j n \omega t_{i}}\right)\left(1+e^{-j n \omega T_{0}}\right) e^{-j n \omega t_{w}},
\end{aligned}
$$

where $t_{w}$ is the delay time of the second pulse train.

Then, the equation of the complex amplitude of the $n$-th harmonic of the sum of two double pulse sequences has the form:

$$
\begin{aligned}
& U_{p}=U_{p 1}+U_{p 2}=\frac{E}{\pi n j}\left(1-e^{-j n \omega t_{i}}\right)\left(1+e^{-j n \omega T_{0}}\right)+ \\
& +\frac{E}{\pi n j}\left(1-e^{-j n \omega t_{i}}\right)\left(1+e^{-j n \omega T_{0}}\right) e^{-j n \omega t_{w}}= \\
& =\frac{E}{\pi n j}\left(1-e^{-j n \omega t_{i}}\right)\left(1+e^{-j n \omega T_{0}}\right)\left(1+e^{-j n \omega t_{w}}\right) .
\end{aligned}
$$

Or, taking into account the transformation in trigonometric form, the equation for the amplitude of the $n$-th spectral component has the form: 
$\left|U_{n}\right|=\frac{4 E}{\pi n}\left(\sin \frac{n \omega t_{i}}{2}\right)\left(\cos \frac{n \omega T_{0}}{2}\right)\left(\cos \frac{n \omega t_{w}}{2}\right)$.

In this case, the zeros of the envelope of the amplitude spectrum are determined by the expressions: $n_{01}=p T / t_{i} ; n_{02}=p^{T} / 2 T_{0} ; n_{03}=p^{T} / 2 t_{w}$,

where $p=1,2,3$, etc.

According to expression (6), the delay time between two pulse sequences can be an informative parameter $t_{w}$.

Determine the change in which amplitudes of the spectral components can be used to measure the change in the delay time $t_{w}$, provided that the influence of the instability of the repetition rate of pulse sequences is maximally reduced. To do this, we define the absolute error affecting the measurement of the change in the amplitude of the $n$-th spectral component. The change in the amplitude $U_{n}$ consists of two parts: the absolute error and the change in the information parameter - the delay time $t_{w}$. Absolute error in obtaining the result of uncorrected changes

in the parameters $E, \omega, t_{i}, T_{0}$ can be determined by the value of the total differential:

$$
\left|\Delta U_{E \omega t_{i} T_{0}}\right|=\frac{d\left|U_{n}\right|}{d E} \Delta E+\frac{d\left|U_{n}\right|}{d \omega} \Delta \omega+\frac{d\left|U_{n}\right|}{d t_{i}} \Delta t_{i}+\frac{d\left|U_{n}\right|}{d T_{0}} \Delta T_{0},
$$

where $\Delta E, \Delta \omega, \Delta t_{i}, \Delta T_{0}$ are respectively, changes in the parameters $E, \omega, t_{i}, T_{0}$.

In this case, the expression for the complete change in the amplitude will be defined as:

$$
\begin{aligned}
& \left|\Delta U_{E \omega t_{i} T_{0} t_{w}}\right|=\frac{d\left|U_{n}\right|}{d E} \Delta E+\frac{d\left|U_{n}\right|}{d \omega} \Delta \omega+\frac{d\left|U_{n}\right|}{d t_{i}} \Delta t_{i}+ \\
& +\frac{d U_{n} \mid}{d T_{0}} \Delta T_{0}+\frac{d\left|U_{n}\right|}{d t_{w}} \Delta t_{w},
\end{aligned}
$$

where $\Delta t_{w}$ are changes in the information parameter $t_{w}$.

After analyzing the partial derivatives of expression (8), we determine the sensitivity to changes in parameters:

$$
\frac{d\left|U_{n}\right|}{d E} \Delta E=\frac{4}{\pi n}\left|\sin \frac{n \omega t_{i}}{2}\right| \cdot \cos \frac{n \omega T_{0}}{2}\left|\cdot \cos \frac{n \omega t_{w}}{2}\right| ;
$$

$$
\begin{aligned}
& \frac{d\left|U_{n}\right|}{d \omega} \Delta \omega=\frac{2 E}{\pi} \mid\left(t_{i} \cos \frac{n \omega t_{i}}{2} \cos \frac{n \omega T_{0}}{2} \cos \frac{n \omega t_{w}}{2}-T_{0} \sin \frac{n \omega t}{2} \sin \frac{n \omega T_{0}}{2} \cos \frac{n \omega t_{w}}{2}-\right. \\
& \left.-t_{w} \sin \frac{n \omega t_{i}}{2} \cos \frac{n \omega T_{0}}{2} \sin \frac{n \omega t_{w}}{2}\right) \mid \operatorname{sign}\left(\sin \frac{n \omega T_{0}}{2} \cos \frac{n \omega T_{0}}{2} \cos \frac{n \omega t_{w}}{2}\right) ; \\
& \frac{d\left|U_{n}\right|}{d t_{i}} \Delta t_{i}=\frac{2 E \omega}{\pi n}\left|\cos \frac{n \omega t_{i}}{2}\right| \cdot \cos \frac{n \omega T_{0}}{2}\left|\cdot \cos \frac{n \omega t_{w}}{2}\right| \operatorname{sign}\left(\sin \frac{n \omega t_{i}}{2}\right) ; \\
& \frac{d\left|U_{n}\right|}{d T_{0}} \Delta T_{0}=-\frac{2 E \omega}{\pi n}\left|\sin \frac{n \omega t_{i}}{2}\right| \cdot \sin \frac{n \omega T_{0}}{2}\left|\cdot \cos \frac{n \omega t_{w}}{2}\right| \operatorname{sign}\left(\sin \frac{n \omega T_{0}}{2}\right) .
\end{aligned}
$$

The minimum sensitivity to a change in noninformational parameters is determined by equating to zero the partial derivatives (9)-(12) and find the extreme of the functions $\left|U_{n}\right|$.

The amplitude-frequency spectrum of a pulse sequence has the property that for certain values of the spectral component $n$, the effect on the amplitude of the instability of the temporal parameters of the pulses decreases. Considering that when forming pulses with the help of existing software-controlled digital means, the instability of the repetition rate of the analyzed signal (for example, the frequency of an industrial network) is orders of magnitude higher than the instability of temporal parameters and the amplitude of the generated pulse signals, all further efforts will be aimed at reducing errors associated specifically with instability of the pulse repetition rate.

The regions of minimum sensitivity to variations in $\omega$ are determined by equating (10) to zero:

$$
\begin{aligned}
& \frac{d\left|U_{n}\right|}{d \omega}=\frac{2 E}{\pi}\left(t_{i} \cos \frac{n \omega t_{i}}{2} \cos \frac{n \omega T_{0}}{2} \cos \frac{n \omega t_{w}}{2}-T_{0} \sin \frac{n \omega t_{i}}{2} \sin \frac{n \omega T_{0}}{2} \cos \frac{n \omega t_{w}}{2}-\right. \\
& \left.-t \sin \frac{n \omega t_{i}}{2} \cos \frac{n \omega T_{0}}{2} \sin \frac{n \omega t_{w}}{2}\right) \operatorname{sign}\left(\sin \frac{n \omega T_{0}}{2} \cos \frac{n \omega T_{0}}{2} \cos \frac{n \omega t_{w}}{2}\right)=0 ; \\
& t_{i} \cos \frac{n \omega t_{i}}{2} \cos \frac{n \omega T_{0}}{2} \cos \frac{n \omega t_{w}}{2}-T_{0} \sin \frac{n \omega t_{i}}{2} \sin \frac{n \omega T_{0}}{2} \cos \frac{n \omega t_{w}}{2}-t_{w} \sin \frac{n \omega t_{i}}{2} \cos \frac{n \omega T_{0}}{2} \sin \frac{n \omega t_{w}}{2}=0 ; \\
& t_{i}-T_{0} \operatorname{tg} \frac{n \omega t_{i}}{2} \operatorname{tg} \frac{n \omega T_{0}}{2}-t_{w} \operatorname{tg} \frac{n \omega t_{i}}{2} \operatorname{tg} \frac{n \omega t_{w}}{2}=0 .
\end{aligned}
$$


Consequently, the condition of minimum sensitivity to the repetition rate of discontinuous sequences must be satisfied if the expression is consistent:

$t_{i}=\operatorname{tg} \frac{n \omega t_{i}}{2}\left(T_{0} \operatorname{tg} \frac{n \omega T_{0}}{2}+t_{w} \operatorname{tg} \frac{n \omega t_{w}}{2}\right)=0$.

To achieve the minimum sensitivity of the parameters of the sequence of pulses to $\omega$, we determine at what values of $T_{0}$ and $t_{i}$ and the range of variation of $t_{w}$, the selected spectral composition will be insensitive to a change in the reference frequency. For the analysis, we introduce the following assumptions:

- spectral composition should not exceed the $15^{\text {th }}$ harmonic due to the difficulty of accurately separating them from the signal;
- duty cycle of pulses in a double pulse sequence is equal to two, i. e. $T_{0}=2 t_{i}$.

Therefore, expression (14) can be represented as:

$$
\begin{aligned}
& \operatorname{tg} \frac{n \omega T_{0}}{4}\left(T_{0} \operatorname{tg} \frac{n \omega T_{0}}{2}+t_{w} \operatorname{tg} \frac{n \omega t_{w}}{2}\right)=\frac{T_{0}}{2} \\
& \operatorname{tg} \frac{T_{0}}{2 \operatorname{tg} \frac{n \omega T_{0}}{4}}-T_{0} \operatorname{tg} \frac{n \omega T_{0}}{4}=t_{w} \operatorname{tg} \frac{n \omega t_{w}}{2} .
\end{aligned}
$$

Let's analyze the sensitivity areas using the Mathcad software with the following parameters of the double pulse sequence: $E=3.3 \mathrm{~V}$, $\omega=314 \mathrm{rad} / \mathrm{sec}, \quad T=20 \mathrm{msec}, \quad T_{0}=0.2 \mathrm{msec}$, $t_{i}=0.1 \mathrm{msec}$ and $t_{w}=0.8 \mathrm{msec}$ (Figure 2).

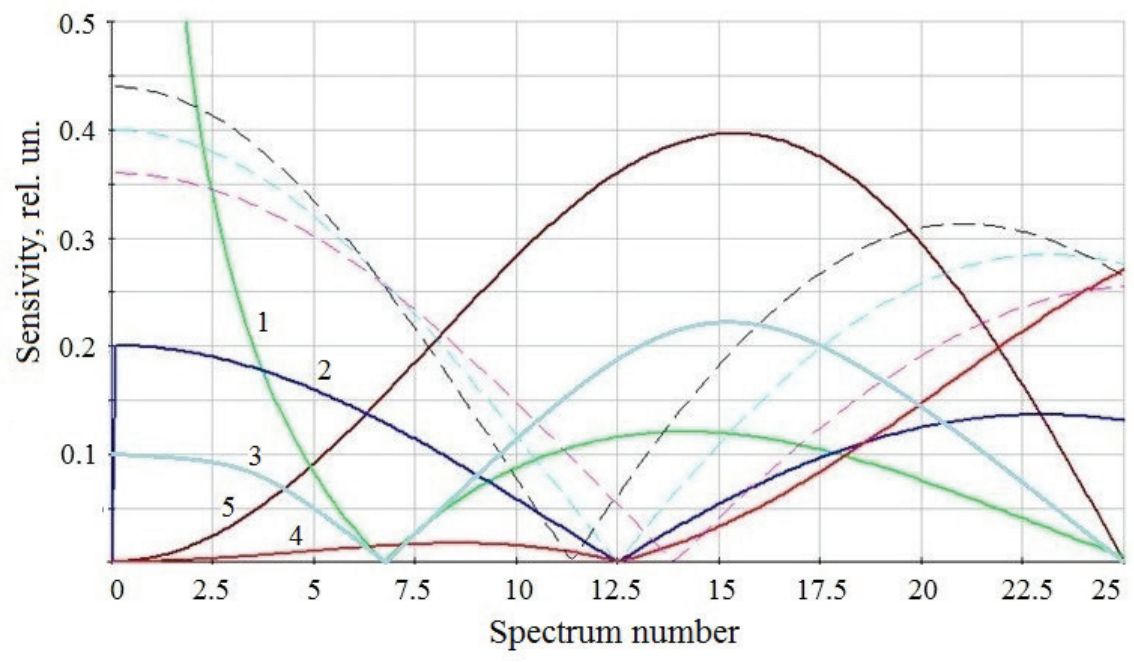

Figure 2 - Dependence of the sensitivity of the amplitude-frequency spectrum on the number of the spectrum of the pulse sequence: 1 - sensitivity to the pulse repetition rate $\omega ; 2$ - sensitivity to pulse duration $t_{i} ; 3$ - sensitivity to the amplitude of the formed pulses $E ; 4$ - sensitivity to the period of pulses in the $T_{0}$ sequence; 5 - sensitivity to the delay time in the pulse sequence $t_{w}$

According to the obtained dependences, it can be concluded that for the selected basic parameters of the pulse sequence, the amplitude of the $7^{\text {th }}$ harmonic does not depend on the change in the repetition rate (i. e. the repetition period of the pulse sequence) and the effect of the instability of the pulse amplitude is significantly reduced with a sufficiently high influence on the change in time delays $t_{w}$.
Let us analyze how changes in the parameters of the pulse sequence $E, t_{i}$ and $T_{0}$ affect the insensitivity region with a change in $\omega$. By analyzing the second derivatives, we determine the influence of the parameters of the pulse sequence on the region of minimum sensitivity to frequency changes:

$\frac{d^{2}\left|U_{n}\right|}{d \omega d E}, \frac{d^{2}\left|U_{n}\right|}{d \omega d t_{i}}, \frac{d^{2}\left|U_{n}\right|}{d \omega d T_{0}}, \frac{d^{2}\left|U_{n}\right|}{d \omega d t_{w}}$.

Then:

$$
\begin{aligned}
& \frac{d^{2}\left|U_{n}\right|}{d \omega d E}=\frac{2}{\pi}\left(t_{i} \cos \frac{n \omega t_{i}}{2} \cos \frac{n \omega T_{0}}{2} \cos \frac{n \omega t_{w}}{2}-T_{0} \sin \frac{n \omega t_{i}}{2} \sin \frac{n \omega T_{0}}{2} \cos \frac{n \omega t_{w}}{2}-\right. \\
& \left.-t_{w} \sin \frac{n \omega t_{i}}{2} \cos \frac{n \omega T_{0}}{2} \sin \frac{n \omega t_{w}}{2}\right) \operatorname{sign}\left(\sin \frac{n \omega T_{0}}{2} \cos \frac{n \omega T_{0}}{2} \cos \frac{n \omega t_{w}}{2}\right) ;
\end{aligned}
$$




$$
\begin{aligned}
& \frac{d^{2}\left|U_{n}\right|}{d \omega d T_{0}}=-\frac{2 E}{\pi}\left(t_{i} \frac{n \omega}{2} \cos \frac{n \omega t_{i}}{2} \sin \frac{n \omega T_{0}}{2} \cos \frac{n \omega t_{w}}{2}+\sin \frac{n \omega t_{i}}{2} \sin \frac{n \omega T_{0}}{2} \cos \frac{n \omega t_{w}}{2}+T_{0} \frac{n \omega}{2} \sin \frac{n \omega t_{i}}{2} \cos \frac{n \omega T_{0}}{2} \cos \frac{n \omega t_{w}}{2}-\right. \\
& \left.-t_{w} \frac{n \omega}{2} \sin \frac{n \omega t_{i}}{2} \sin \frac{n \omega T_{0}}{2} \sin \frac{n \omega t_{w}}{2}\right) \operatorname{sign}\left(\sin \frac{n \omega t_{i}}{2} \cos \frac{n \omega T_{0}}{2} \cos \frac{n \omega t_{w}}{2}\right) ; \\
& \frac{d^{2}\left|U_{n}\right|}{d \omega d t_{i}}=\frac{2 E}{\pi}\left(\cos \frac{n \omega t_{i}}{2} \cos \frac{n \omega T_{0}}{2} \cos \frac{n \omega t_{w}}{2}-t_{i} \frac{n \omega}{2} \sin \frac{n \omega t_{i}}{2} \cos \frac{n \omega T_{0}}{2} \cos \frac{n \omega t_{w}}{2}-T_{0} \frac{n \omega}{2} \cos \frac{n \omega t_{i}}{2} \sin \frac{n \omega T_{0}}{2} \cos \frac{n \omega t_{w}}{2}-\right. \\
& \left.-t_{w} \frac{n \omega}{2} \cos \frac{n \omega t_{i}}{2} \cos \frac{n \omega T_{0}}{2} \sin \frac{n \omega t_{w}}{2}\right) \operatorname{sign}\left(\sin \frac{n \omega t_{i}}{2} \cos \frac{n \omega T_{0}}{2} \cos \frac{n \omega t_{w}}{2}\right) ; \\
& \frac{d^{2}\left|U_{n}\right|}{d \omega d t_{w}}=-\frac{2 E}{\pi}\left(t_{i} \frac{n \omega}{2} \cos \frac{n \omega t_{i}}{2} \cos \frac{n \omega T_{0}}{2} \sin \frac{n \omega t_{w}}{2}-T_{0} \frac{n \omega}{2} \sin \frac{n \omega t_{i}}{2} \sin \frac{n \omega T_{0}}{2} \sin \frac{n \omega t_{w}}{2}+\sin \frac{n \omega t_{i}}{2} \cos \frac{n \omega T_{0}}{2} \sin \frac{n \omega t_{w}}{2}+\right. \\
& \left.+t_{w} \frac{n \omega}{2} \sin \frac{n \omega t_{i}}{2} \cos \frac{n \omega T_{0}}{2} \cos \frac{n \omega t_{w}}{2}\right) \operatorname{sign}\left(\sin \frac{n \omega t_{i}}{2} \cos \frac{n \omega T_{0}}{2} \cos \frac{n \omega t_{w}}{2}\right) .
\end{aligned}
$$

Let's analyze the sensitivity areas using the Mathcad software with the previously indicated parameters of the signal under study (Figure 3).

According to the data obtained, it can be concluded that for the indicated parameters of the sum of double pulse sequences, the amplitude of the seventh harmonic does not depend on the instability of the carrier frequency and, at the same time, has a minimum sensitivity to changes in the pulse duration $t_{i}$, the period of pulses in the sequence $T_{0}$ and the amplitude of the pulses $E$, and the sensitivity from the change in the delay time in the pulse sequence $t_{w}$ is commensurate with the maximum.
Analyzing the presented dependences, it can be concluded that by choosing the parameter $T_{0}$, it is possible to measure the changes in the delay time from the amplitude-spectral components that are in the region of insensitivity to the instability of the carrier frequency and with a significant decrease in the influence of the instability of other parameters: the pulse amplitude $E$, the period of the pulses in the sequence $T_{0}$ and pulse duration $t_{i}$.

The proposed technique can be implemented using a measuring system, the block diagram of which is shown in Figure 4.

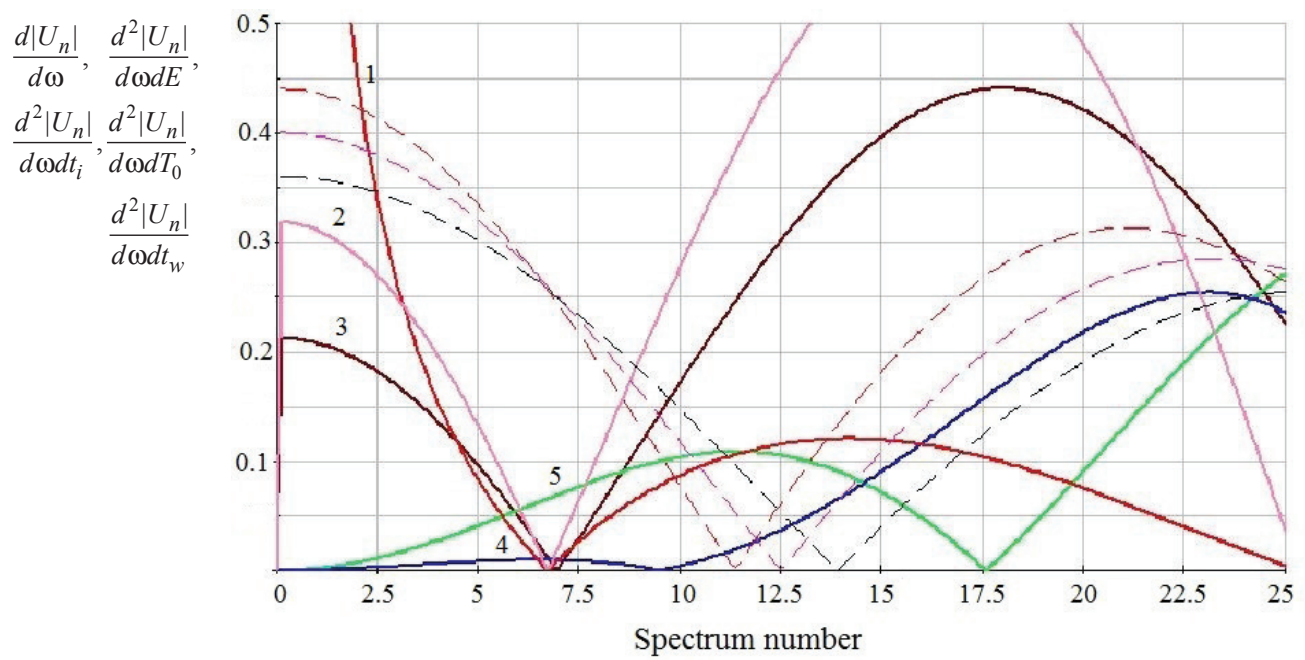

Figure 3 -Dependences of the influence of the main parameters of a discontinuous pulse sequence on changes in the carrier frequency from its spectrum: 1 - sensitivity of the amplitude-frequency spectrum to changes in the carrier frequency $\omega ; 2$ - the effect of changing the carrier frequency on the instability of the amplitude of the pulses $E ; 3-$ the effect of changing the carrier frequency on the instability of the pulse duration $t_{i} ; 4$ - the effect of changing the carrier frequency on the instability of the period of pulses in the sequence $T_{0} ; 5$ - the effect of changing the carrier frequency on the instability of the delay time in the pulse sequence $t_{w}$ 


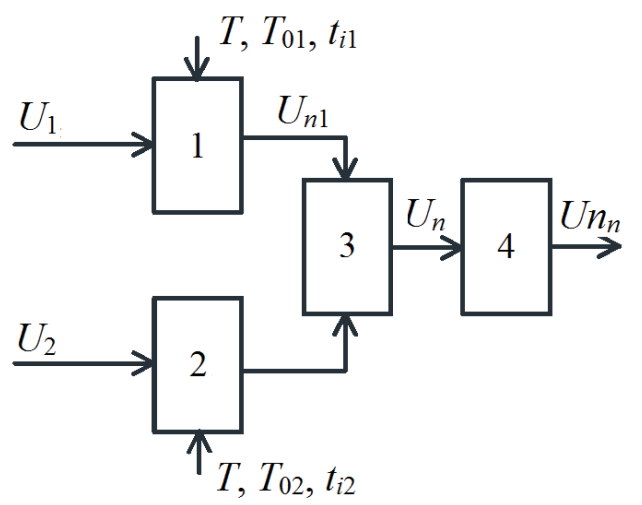

Figure 4-Block diagram of a measuring system for measuring changes in time parameters: 1 - block of pulse shapers no. $1 ; 2-$ block of pulse shapers no. $2 ; 3$ - mixer; 4 - selective device

The measuring system contains two blocks of pulse shapers 1 and 2, an analog addition circuit (mixer) 3 and a selective device 4 . The operation of the measuring system in the form of a timing diagram is shown in Figure 5 and looks as follows.

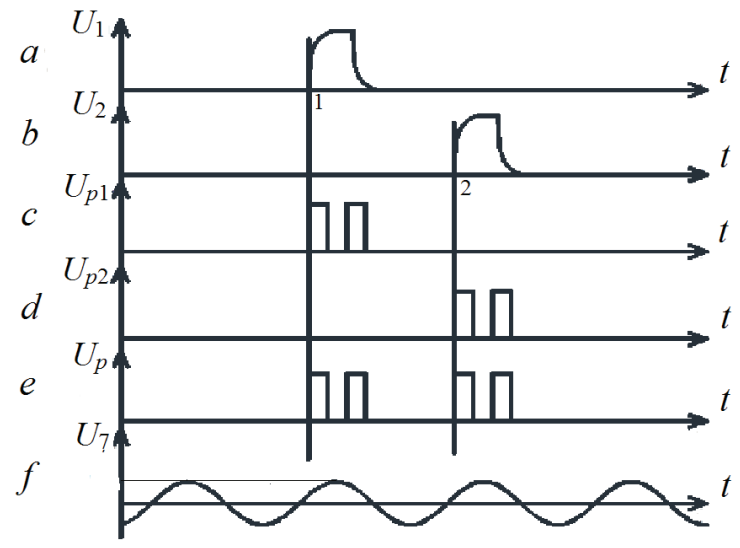

Figure 5 - Operation of a measuring system for measuring changes in time parameters: $a$-pulse signal no. 1 ; $b$-pulse signal no. $2 ; c$-double pulse sequence no. 1 ; $d$-double pulse sequence no. $2 ; e$-double discontinuous pulse sequence; $f$ - resulting informative harmonic

The input of the measuring system, which is two blocks of pulse shapers 1 and 2, is supplied with two pulse signals $U_{1}$ and $U_{2}$ (respectively, Figures $5 a$ and $5 b$ ), between which it is necessary to control the change in time parameters. With the help of blocks of pulse shapers in accordance with the specified control parameters $T_{0}$ is the period of the pulse sequence, $t_{i}$ is the duration of the pulses and the period of the input signals $T$, two pulse sequences are formed (respectively, Figures $5 c$ and $5 d$ ). Then these pulse sequences in mixer 3 are converted into one total sequence, which is a double discontinuous pulse sequence (Figure $5 e$ ) with the parameters: $T_{0}$ is period of the pulse sequence; $t_{i}$ is the duration of the pulses; $t_{w}$ is the delay time between pulses. The required informative harmonic is allocated on the selection device 4 (Figure $5 f$ ), by analyzing the amplitude of which it is possible to judge the measured time interval.

One of the examples of using the presented technique is measuring the parameters of the noload current of electrical machines, i. e. diagnostics of the condition of the windings when the machine is running. In this case, the system has the initial parameters: the amplitude of the pulse sequence is $E=3.3 \mathrm{~V}$, the frequency of the supply network is $50 \mathrm{~Hz}(\omega=314)$. According to the studies and real possibilities, it was determined that it is most optimal to use the period of pulses in a sequence equal to within 0.01 of the nominal value of the input signal period and with a duty cycle of these pulses equal to two. From here we determine the parameters of the pulse sequence: $T=20 \mathrm{msec}, T_{0}=0.2 \mathrm{msec}$, $t_{i}=0.1 \mathrm{msec}$.

From expressions (8) and the obtained equations (9)-(12), we determine the errors associated with the instability of non-informative parameters, where: $\Delta E=10^{-3} \mathrm{~V} ; \Delta \omega=3 \mathrm{rad} / \mathrm{sec}$; $\Delta t_{i}=\Delta T_{0}=10^{-8} \mathrm{sec}$, the informative parameter is set within $t_{w}=4 T_{0}=0.8 \mathrm{msec}$ at $n=7$.

Consequently:

$\left|\Delta U_{E \omega t_{i} T_{0}}\right|=6.637 \cdot 10^{-5}$.

This means that the measurement error, including those associated with the instability of the main parameters of the pulse sequence, will be less than $0.01 \%$, and therefore the accuracy with respect to frequency with its instability improves by two orders of magnitude.

\section{Conclusion}

A spectral method for measuring time intervals, as well as their changes by analyzing pulse sequences, formed on the basis of characteristic points of the measured signal, is proposed. For this, a double pulse sequence is considered, an equation for the amplitudes of its spectral components is obtained, and, in accordance with this, it is determined that the delay time between double pulses is the most informative parameter. 
Further, using the Mathcad software, we analyzed the sensitivity regions for changes in the main parameters of the pulse sequence, namely the repetition rate, as the main destabilizing factor.

The considered method makes it possible to increase the accuracy of measuring time intervals due to the almost complete elimination of the influence of the instability of the reference frequency and the amplitude of the generated pulses, which is unattainable with modern hardware, including digital signal processing.

\section{References}

1. Zhuk A., Pligin E.A., Lyagin A.M. Roman'ko D.V., Pletukhina A.A. Tsifrovoy sposob izmereniya fazovogo sdviga garmonicheskikh kolebaniy, [Digital method for measuring the phase shift of harmonic oscillations]. Patent RU, no. 2419098C2, 2011-05-20 (in Russian).

2. Gol'dshteyn E.I., Batseva N.L. Sposob opredeleniya sdviga faz mezhdu dvumya sinusoidal'nymi signala$m i$ [Method for determining the phase shift between two sinusoidal signals]. Patent BY, no. 19224C1, 2005-11-20.

3. Abhaikumar V., Raju S., Deepak Ram Prasath S., Senthilkumar R., Vasikaran P. Devices and methods for phase shifting a radio frequency (RF) signal for a base station antenna. Patent US, no. 8862063B2, 2014-10-14.

4. Shemigon N.N., Kukushkin S.S., Gladkov I.A. Sposob opredeleniya dal'nosti do ob"yekta s istochnikom izlucheniya signalov s raznymi chastotami [Method for determining the distance to an object with a source of radiation of signals with different frequencies]. Patent RU, no. 2469349, 2013-03-19 (in Russian).

5. Sukhodolov YU.V., Kish O.I., Pasikunov N.V. Sposob opredeleniya dal'nosti tseli [Method for determining the target range]. Patent BY, no. 19224C1, 2015.06.30

6. Wolfgang Maichen. Digital Timing Measurements. From Scopes and Probes to Timing and Jitter, Teradyne Inc.Agoura HillsUSA, 2006, 240 p.

7. Patyukov V.G., Patyukov E.V. Sposob tsifrovogo izmereniya ditel'nosti vremennykh intervalov [Method for digital measurement of the duration of time intervals]. Patent RU, no. 2414736, 2011-03-20 (in Russian).

8. Tutygin V.S. Sposob izmereniya vremennykh intervalov mezhdu radioimpul'sami [Method for measuring time intervals between radio pulses]. Patent RU, no. 2456632, 2012-07-20 (in Russian).

9. Bezmaternykh N.F., Vayts S.V., Zlygostev A.M., Makarenko S.L., Palkin S.M., Toropitsyn S.V. Sposob izmereniya vremennykh intervalov elektricheskikh signalov [Method for measuring time intervals of electrical signals]. Patent RU, no. 02162243, 20.01.2001 (in Russian).

10. Sukhodolov YU.V., Kish O.I., Kruchenok L.P. Sposob opredeleniya vremeni zaderzhki mezhdu dvumya periodicheskimi posledovatel'nostyami impul'sov [Method for determining the delay time between two periodic pulse trains]. Patent BY, no. 19225S1, 2015.06.30

11. Kharkevich A.A. Spektry $i$ analiz [Spectra and Analysis]. Izd. 6, Moscow, URSS, 2018, 240 p. 